\author{
Кулаковская Т.A. \\ кандидат экономических наук, доцент \\ E-mail: tatyana_kula@mail.ru \\ Дерменжи Д.Ф. \\ студент \\ кафедра экономики промышленности \\ Одесская национальная академия пищевых технологий \\ ул. Канатная, 112, г. Одесса, Украина, 65039 \\ E-mail: dinochka19950314@mail.ru.
}

\title{
СУЩНОСТЬ УКРАИНСКОГО ПРЕДПРИНИМАТЕЛЬСТВА, ЕГО МЕСТО В МИРЕ И ПЕРСПЕКТИВЫ РАЗВИТИЯ
}

В статье рассмотрены особенности украинского предпринимательства, основные отличия ведения бизнеса в Украине и в западноевропейских странах. Проанализировано отношение людей к самозанятости, степень готовности заняться собственным делом и их прогнозы о будущем предпринимательства. Были выявлены основные проблемы развития бизнеса в Украине и Европе, пути их решения на основе анализа перспектив развития предпринимательства, проведенного компанией «Amway Украина» и при поддержке Украинского союза промышленников и предпринимателей в 2014 году.

Ключевые слова: предпринимательство, социальное предпринимательство, прибыль, самозанятость, государственное регулирование, налогообложение.

Постановка проблемы и ее связь с важными научными и практическими задачами. В условиях тяжелой политической и экономической ситуации в Украине развитие предпринимательства, в частности малого и среднего бизнеса, является одним из важнейших факторов социально-экономического роста и важной составляющей конкурентоспособности национальной экономики. На данном этапе развития страны эти вопросы крайне важны, так как предпринимательство обеспечивает не только материальную стабильность населения, но и развивает интеллектуальные, нравственные, культурные и другие качества человека.

Анализ последних публикаций по проблеме. В последних публикациях, посвященных исследованию предпринимательства в Украине, большое внимание уделяется развитию малого и среднего бизнеса, ведь предприятия, которые не требуют крупных стартовых инвестиций и гарантируют высокую скорость оборота ресурсов, имеют наибольший потенциал быстро и экономично решать проблемы реструктуризации экономики, формирования и насыщения рынка потребительскими товарами в условиях падения экономики и ограниченности финансовых ресурсов.

Формулирование целей исследования. Целью данной работы является: исследовать особенности ведения бизнеса в Украине, определить проблемы и пути их решения, а также степень готовности населения заниматься бизнесом.

Предпринимательство - это не всякий бизнес, это стиль хозяйствования, которому присущи принципы новаторства, антибюрократизма, постоянной инициативы, ориентации на нововведения в процессы производства, маркетинга, распределения и потребления товаров и услуг.
Предпринимательство можно определять с различных позиций как:

- деятельность, направленную на максимизацию прибыли;

- инициативную деятельность граждан, заключающуюся в выработке товаров и услуг, направленную на получение прибыли;

- прямую функцию реализации собственности, основную ее производственную функцию;

- процесс организационной новации в целях извлечения прибыли;

- действия, направленные на возрастание капитала, развитие производства и присвоение прибыли;

- специфический вид деятельности, направленный на неустанный поиск изменений в существующих формах жизни предприятий и общества, постоянная реализация этих изменений.

Ведение бизнеса в Украине значительно отличается от ведения бизнеса в других странах, особенно в таких, как США, Германия, Великобритания и в других западноевропейских странах. Основные отличия заключаются в таких факторах, как [3]:

1) Украинское чувство личной ответственности.

Главное отличие между украинским и западным мышлением заключается в том, что люди запада при ведении бизнеса стремятся взять на себя как можно больше личной ответственности и рассчитывают в большей мере на собственные силы, а вот с украинцами дело обстоит совсем иначе. В Украине вся ответственность перекладывается на группу. Виновником данной проблемы являются государственные органы, которые создают постоянные бюрократические проволочки, требуют дополнительных документов и не нужной формальности. 
2) Пунктуальность и надежность в Украине.

Иностранцы должны привыкнуть, что опоздание на встречу является нормой для украинцев. Опоздать на пять-десять минут или прибыть за пятнадцать минут до окончания встречи или собрания считается нормальным. Эта черта может очень обострить отношения между украинскими и иностранными партнерами по бизнесу.

3) Личные связи.

Украинцы предпочитают договариваться о встречах и обсуждать деловые вопросы лично, в то время как на западе чаще используются телефонные и видео конференции. Возможно, это и лучше, так как при личном контакте легче судить о намерениях партнера и надежности решения всякого рода проблем.

\section{4) Лидерство.}

Стиль руководства в украинских организациях имеет много различий с иностранным стилем Запада. Уже говорилось о том, что украинцы в большинстве случаев не берут на себя личную ответственность, что не скажешь об их иностранных коллегах, которых готовят к руководящей роли, начиная с детского сада. После получения лидирующих должностей, многие украинцы становятся довольно авторитарными по отношению к своим коллегам. Среди западных управленцев преобладает стиль демократического и равноправного руководства. В Украине руководители концентрируют все свои полномочия по принятию решений в своих собственных руках и требуют от своих сотрудников безукоризненного подчинения.

Украине.

5) Дискриминация при трудоустройстве в

В большинстве имеющихся вакансий в Украине указывать пол, возраст и другие личные данные является правилом. При составлении резюме эта и другая личная информация, такая как семейное положение, является обязательной. На Западе данный вопрос понятен с точки зрения работодателя, но абсолютно неприемлем с точки зрения этического смысла и современных представлений о правах человека.

Несмотря на сложную политическую и экономическую ситуацию в стране, предпринимательство в Украине развивается. Одним из новшеств данной отрасли, которое появилось несколько лет назад, является социальное предпринимательство.

Социальное предпринимательство - пока новое для Украины понятие. Соответственно, и трактуют его по-разному. Главное отличие социального предпринимательства от обычного в том, что прибыль предприятия направляется на решение социальных проблем. В остальном оно полностью подчиняется законам бизнеса: уплачиваются налоги, планируется развитие, приносит прибыль. Сегодня социальное предпринимательство во всем мире стало признанным инновационным способом решения проблем экономического развития, преодоления бедности, создания новых рабочих мест, сохранения окружающей среды. Одним из мировых лидеров в развитии данной отрасли является Великобритания. В Украине примером служит медицинский реабилитационный центр «Здоровье» из Новоазовска Донецкой области, который предоставляет существенные скидки на лечение и реабилитацию больных из малообеспеченных категорий населения, и пекарня «Горіховий дім» во Львове, прибыль от которой учредители направляют на поддержку кризисного центра для женщин и другие социальные проекты.

Bce эти вопросы крайне актуальны для Украины. Именно поэтому в 2010 году стартовал проект «Развитие социального предпринимательства». В консорциум, реализующий проект, вошли Фонд «Восточная Европа», Британский совет, Международный фонд «Відродження», «Pricewaterhouse Coopers в Україні», Эрсте Банк, Украинский фонд поддержки предпринимательства.

Основным барьером в развитии сектора партнеры проекта считают недостаточную информированность предпринимателей и отсутствие у них знаний в этой области.

Также Украинский фонд поддержки предпринимательства и компания «Amway Украина» в 2014 году инициировали конференцию по развитию предпринимательства в Украине «Перспективы экономики Украины: стратегии развития малого и среднего бизнеса».

Во время обсуждения были выделены 5 основных задач для улучшения бизнес-климата в Украине [2]:

- формирование доверительных отношений - среди бизнес-игроков и с государственными структурами, сотрудничество и поддержка друг друга, как по горизонтали, так и по вертикали;

- обеспечение стабильной налоговой системы - должны быть прекращены постоянные эксперименты с Налоговым кодексом и, наконец, установлена простая, прозрачная, понятная система;

- объединение усилий - для внедрения качественных изменений необходимо создать единую платформу для обмена опытом и общения между правительством, бизнесом и общественными бизнесобъединениями;

- распространение информации об имеющихся бизнес-возможностях - различные гранты и поддержка со стороны общественных и международных организаций;

- формирование бизнес-культуры - бизнес-отношения требуют равной ответственности всех участников процесса - как государства, так и предпринимателей.

Также на конференции были представлены такие показатели, как:

1. Отношение населения к идее самозанятости. Как видно на рис. 1, 72,1 \% украинцев поддерживают эту идею, что является вполне положительной чертой. 


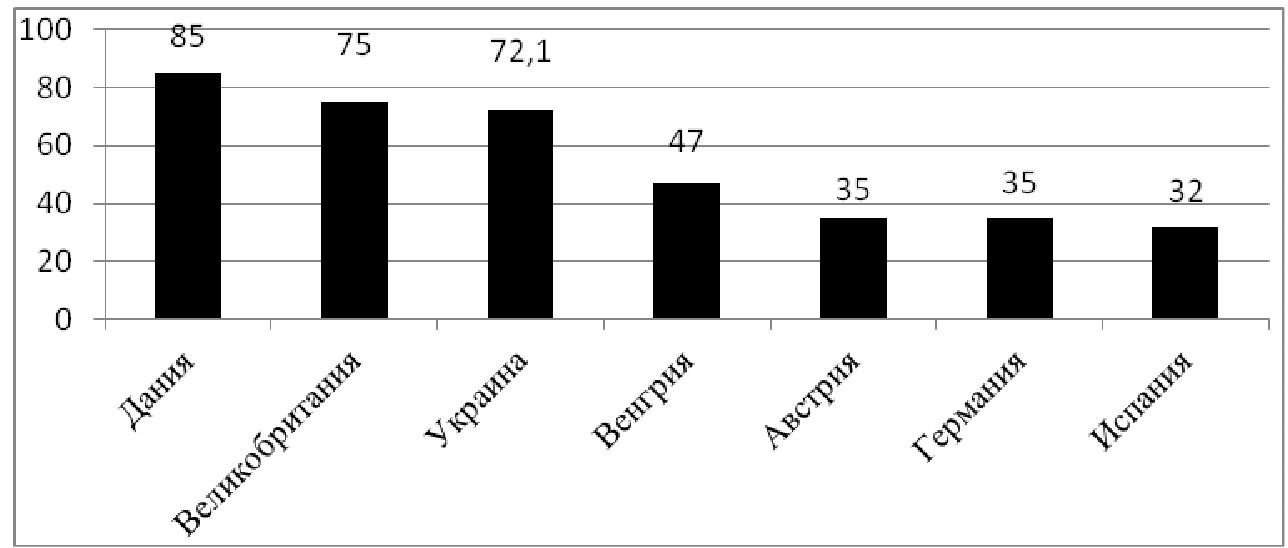

Рис. 1. Отношение населения к идее самозанятости по странам, \%

2. Степень реальной готовности заняться бизнесом. В Украине всего лишь 38,1\% людей готовы заняться бизнесом. Это соответствует среднему показателю по Европе, но все же есть потенциал стремиться дальше, ведь в Греции этот показатель составляет $50 \%$, хотя в Германии $-28 \%$.
3. Ключевые мотивы к созданию собственного бизнеса. Так как Украина стремиться попасть на европейский рынок, то вполне уместным будет рассматривать их в сравнении с Европой, что и показано на рис. 2.

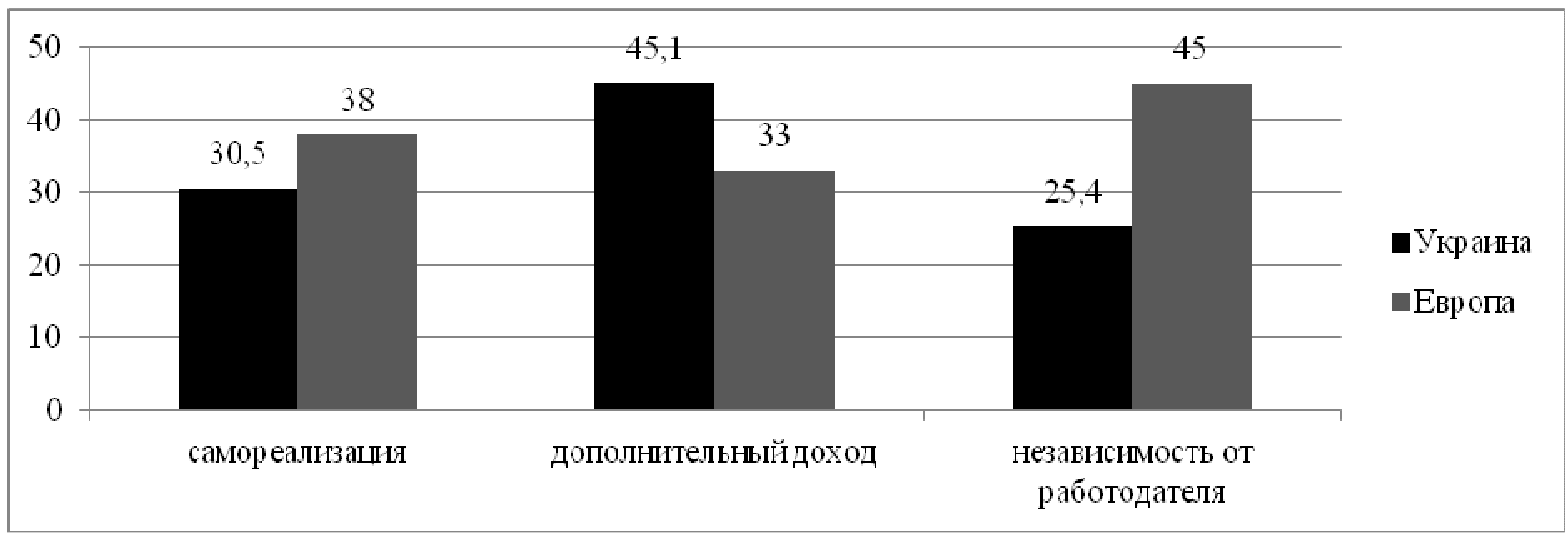

Рис. 2. Мотивы создания собственного бизнеса

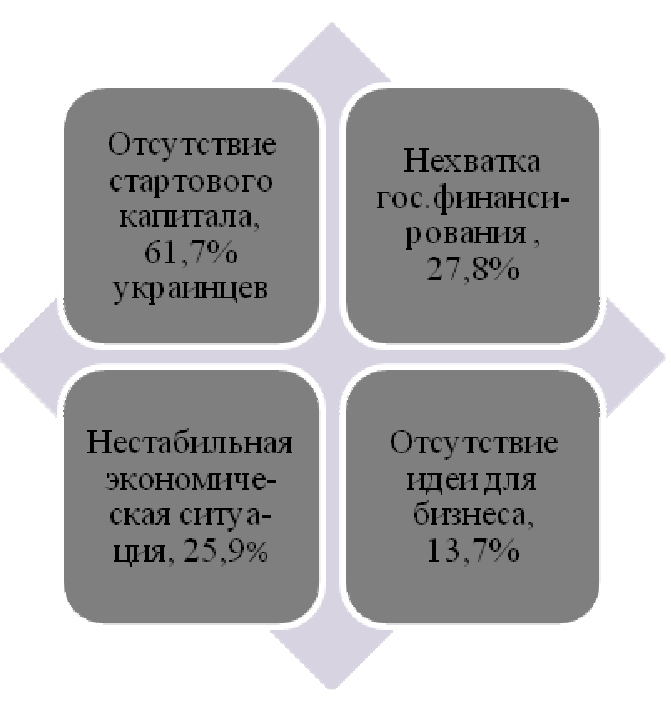

Рис. 4. Европа

4. Основные препятствия на пути к самозанятости. Как и предыдущий показатель, его следует анализировать в сравнении с Европой. На рис. 3 и

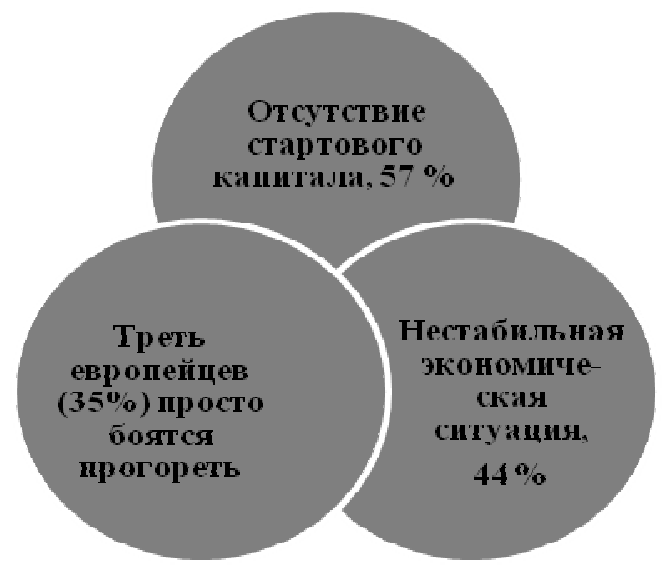

Рис. 3. Украина

рис. 4 , соответственно, изображены процентные соотношения основных факторов, препятствующих развитию предпринимательства, по мнению населения. 
5. Значимость предпринимательства - прогнозы на будущее. По данным исследования Amway, 44,4\% украинцев думают, что в течение десяти последующих лет самозанятость останется такой же востребованной, 31,2\% - верят в то, что ее значимость даже возрастет.

Европа дает еще более оптимистичный прогноз для развития предпринимательской деятельности - три из четырех опрошенных (78\%) считают, что самозанятость, несомненно, будет набирать обороты.

Выводы и перспективы дальнейших исследований. Без успешной работы малых и средних предприятий в Украине невозможно построить нормальную систему экономических связей. Сейчас можно выделить три главные проблемы малого и среднего бизнеса в Украине: кредитование, государственное регулирование и налогообложение бизнессектора. Чтобы их преодолеть, необходимо одно объединить усилия всех участников рынка - государства, бизнеса, общественных бизнес-объединений. Только тогда Украина сможет сделать действительно эффективные шаги. Это и может стать основными направлениями дальнейших исследований.

\section{Литература}

1. Сафаров Э. Развитие малого и среднего бизнеса в Украине. / Э. Сафаров, А. Билль, А.М. Лисанов. [Электронный ресурс]. - 2012. - Режим доступа : http://www.rusnauka.com/16_NPRT_2013/Economics/15 _140012.doc.htm.

2. Конференция «Перспективы экономики Украины: стратегии развития малого и среднего бизнеса» [Электронный ресурс]. - 2014. - Режим доступа : http://news.amway.ua.

3. Портал гражданской журналистики «Украинская бизнес культура» [Электронный ресурс]. - Режим доступа : http://h.ua/story/302670/.

4. Административно-управленческий портал «Предпринимательство и его место в экономике страны» [Электронный ресурс]. - Режим доступа : http://www.aup.ru/books/m72/1_1.htm.

5. Главный сайт компании Amway «Украина в контексте Европы» [Электронный ресурс]. - Режим доступа : http://news.amway.ua.

6. Предпринимательство как общественное, социальное и политическое явление. [Электронный ресурс]. - Режим доступа : http://moyuniver.net/predprinimatelstvo-kak-obshhestvennoe-socialnoe-i-politicheskoeyavlenie/.

7. Украинский бизнес портал «Социальное предпринимательство» [Электронный ресурс]. - Режим доступа : http://ubp.com.ua/biz/164/0.

Статья поступила 20.04.2015

Кулаковська Т.A.

кандидат економічних наук, доцент

E-mail: tatyana_kula@mail.ru

Дерменжі Д.Ф.

студент

кафедра економіки промисловості

Одеська національна академія харчових технологій

вул. Канатна, 112, м. Одеса, Україна, 65039

E-mail: dinochka19950314@mail.ru.

\section{СУТНІСТЬ УКРАЇНСЬКОГО ПІДПРИЕМНИЦТВА, ЙОГО МІСЦЕ У СВІТІ ТА ПЕРСПЕКТИВИ РОЗВИТКУ}

У статті представлені результати дослідження з підприємництва, в тому числі основних рис середнього та малого бізнесу як основного двигуна розвитку національної економіки. Розглянуто основні позиції, які визначають його сутність, а також найяскравіші відмінності у веденні бізнесу в Україні від ведення бізнесу в Європі з позиції відносин і поведінки людей. Розглянуті такі відмінності, як: почуття особистої відповідальності, пунктуальність і надійність, особисті зв'язки, дискримінація при працевлаштуванні. Одним з нових і пріоритетних напрямів розвитку українського бізнесу є соціальне підприємництво, особливість якого полягає в тому, що прибуток підприємства спрямовується на вирішення соціальних проблем. В Україні вже існують приклади таких підприємств і створюються умови для їх подальшого просування на ринок. Також у статті наводиться аналіз результатів конференції компанії «Amway Україна» «Перспективи економіки України: стратегії розвитку малого та середнього бізнесу». Були виділені ТОП-5 ключових завдань для поліпшення бізнес-клімату в Україні: формування довірчих відносин, забезпечення стабільної податкової системи, об'єднання зусиль, поширення інформації про наявні бізнес-можливості та формування бізнес-культури. На даній конференції були наведені також показники, які характеризують ставлення населення до підприємництва, ступінь готов- 
ності зайнятися власним бізнесом, ключові мотиви і перешкоди на шляху до самозайнятості, і дана їх порівняльна характеристика по країнах. У статті представлені дані про прогнози розвитку підприємництва в майбутньому, які є цілком оптимістичними і свідчать про його затребуваність. Зроблено висновки про те, що, тільки об'єднавши зусилля всіх учасників ринку, можна зробити ефективні кроки в бік поліпшення економічної ситуації в країні і вирішення основних проблем малого та середнього бізнесу.

Ключові слова: підприємництво, соціальне підприємництво, прибуток, самозайнятість, державне регулювання, оподаткування.

\author{
Kulakovska T.A. \\ Ph.D. in Economics, Associate Professor \\ E-mail: tatyana_kula@mail.ru \\ Dermenzhi D.F. \\ student \\ Department of Industrial Economics \\ Odessa National Academy of Food Technologies \\ Kanatna str., 112, Odessa, Ukraine, 65039 \\ E-mail: dinochka19950314@mail.ru
}

\title{
THE ESSENCE OF THE UKRAINIAN BUSINESS, HIS PLACE IN THE WORLD AND PROSPECTS OF DEVELOPMENT
}

In this article, we explore the business, including the main features of small and medium businesses as the main engine of the national economy. The main items that define its essence and the brightest differences in doing business in Ukraine from doing business in Europe from the perspective of relationships and behavior. Allocate such differences as a sense of personal responsibility, punctuality and reliability, personal communication, discrimination in employment. One of the new and the priorities of Ukrainian business is social enterprise, a feature of which is that the profit of the enterprise is directed to the solution of social problems. In Ukraine there are already examples of such enterprises and creates conditions for further market promotion. The article also provides an analysis of conference of the company "Amway Ukraine» "Prospects of Ukraine's economy: development strategy for small and medium businesses." Were allocated the top 5 key objectives to improve the business-climate in Ukraine: the formation of trust relationships, providing a stable tax system, unification of efforts, dissemination of information on available business opportunities and formation of business-culture. At the conference were considered as indicators that characterize the attitude of the population towards entrepreneurship, readiness to do their own business, the key motivations and barriers to self-employment, and given their comparative characteristics of the countries. In the article there are data on forecasts of business development in the future, which are quite optimistically and testify to its relevance, and given conclusions about that by combining the efforts of all market participants can make effective steps towards improving the economic situation in the country and address the major problems of small and medium-sized businesses.

Keywords: entrepreneurship, social entrepreneurship, income, self-employment, government regulation and taxation.

\section{References}

1. Safarov E., Bil A., Lisanova A. M. (2012). «Razvitie malogo i srednego biznesa v Ukraine» [Elektronnyiy resurs]. Rezhim dostupa: http://www.rusnauka.com/16_NPRT_2013/Economics/15_140.

2. Konferentsiya «Perspektivyi ekonomiki Ukrainyi: strategii razvitiya malogo i srednego biznesa» (2014). [Elektronniy resurs]. Rezhim dostupa: http://news.amway.ua.

3. Portal grazhdanskoy zhurnalistiki «Ukrainskaya biznes kultura». [Elektronniy resurs]. Rezhim dostupa: http://h.ua/story/302670/.

4. Administrativno-upravlencheskiy portal «Predprinimatelstvo i ego mesto v ekonomike stranyi» [Elektronniy resurs] Rezhim dostupa: http://www.aup.ru/books/m72/1_1.htm.

5. Glavnyiy sayt kompanii Amway «Ukraina v kontekste Evropyi». [Elektronniy resurs]. Rezhim dostupa: http://news.amway.ua.

6. Predprinimatelstvo kak obschestvennoe, sotsialnoe i politicheskoe yavlenie. [Elektronniy resurs]. Rezhim dostupa: http://moyuniver.net/predprinimatelstvo-kak-obshhestvennoe-socialnoe-i-politicheskoe-yavlenie/.

7. Ukrainskiy biznes portal «Sotsialnoe predprinimatelstvo». [Elektronniy resurs]. Rezhim dostupa: http://ubp.com.ua/biz/164. 